\title{
What is the role of weather in cardiovascular disease?
}

\author{
Dr Krishnan Bhaskaran \\ Dr Shakoor Hajat \\ Professor Liam Smeeth
}

London School of Hygiene and Tropical Medicine, UK

Keywords: ambient temperature, climate, cardiovascular disease, myocardial infarction, epidemiology

Cardiovascular disease is a leading cause of death worldwide $\mathrm{e}^{1-2}$ and is the single largest cause of excess mortality in winter. ${ }^{3}$ Because increasing age is the major determinant of cardiovascular risk, any factor that increases the risk of cardiovascular disease will have the greatest impact among older people. ${ }^{4}$ Seasonal patterns and in particular winter increases in mortality from cardiovascular disease have been documented in research spanning at least seven decades, ${ }^{5-6}$ but the precise role of weather is difficult to infer from studies of seasonal variation: different seasons might also reflect differing behaviours, differing levels of infectious diseases, differing levels of activity, and other unmeasured confounders.

Recent advances in epidemiologic methods allow seasonal factors to be disentangled from the acute effects of weather, and a body of research has built up focussing on the short-term associations between ambient outdoor temperature in particular, and health outcomes. A noteworthy study conducted in 11 US cities demonstrated a U-shaped relationship between temperature and all-cause mortality: mortality was observed to decrease as temperatures increased from the coldest days up to a certain threshold temperature, above which mortality increased with temperature, ${ }^{7}$ similar patterns have been observed in developing countries. ${ }^{8}$ As well as overall mortality, ambient outdoor temperature has also been linked to mortality from specific causes, notably cardiovascular diseases (CVDs); again Ushaped relationships have been described, ${ }^{9}$ and studies have shown increases in CVD mortality associated both with cold ${ }^{10}$ and hot ${ }^{11}$ outdoor temperatures. These effects may operate with some delay, or "lag": while heat is commonly associated with immediate (same day or next day) increases in mortality, cold effects have been found to operate up to several weeks after the temperature reduction. ${ }^{12}$

Cardiovascular disease of course covers a spectrum of conditions; what are the specific conditions driving these temperature-mortality associations? There has been recent interest in the effects of temperature on myocardial infarction (MI). Our recent systematic review suggested compelling evidence that temperature is related to the risk of $\mathrm{Ml}$, but was inconclusive on the size or indeed direction of the effect. Among the 12 studies included that had data from the winter season, 8 found a statistically significant increased risk of MI at colder temperatures. Similarly, 7 out of 13 relevant studies found a statistically significant detrimental effect of heat. Effect estimates ranged from a $7 \%$ to a $40 \%$ increase in $\mathrm{MI}$ rates on days with the most extreme temperatures. ${ }^{13}$ Of note, only a handful of studies controlled for potentially important confounding variables such as air pollution and circulating influenza levels which could be associated with both temperature and MI risk. A recent analysis using data from England and Wales in which we attempted to address these methodological weaknesses suggested that temperature reductions (but not temperature increases) were associated with increased $\mathrm{MI}$ risk: each $1^{\circ} \mathrm{C}$ drop in temperature was associated with a $2 \%$ increase in $\mathrm{Ml}$ risk (equating to around 200 extra heart attacks, based on UK rates) over the current and subsequent 28 days, with the highest risk increase between 2 days and 2 weeks following exposure. ${ }^{14}$ 
Might certain groups be more vulnerable to the effects of temperature? Interestingly, data from England and Wales suggested that the increase in $\mathrm{MI}$ risk associated with lower temperatures was larger among older individuals, but only up to a point: those aged 85+ years were less vulnerable than younger age groups, a finding that might be explained by a tendency for the very elderly to live in residential or care homes with good heating, and to spend less time outdoors. ${ }^{14}$ Evidence from mortality studies also most commonly indicates larger temperature-mortality associations among the elderly, ${ }^{10}$ though results are not entirely consistent, with a few studies suggesting similar temperature effects across age groups ${ }^{7}$ and some data even suggesting stronger effects in younger individuals. ${ }^{15} \mathrm{~A}$ few other potential effect modifiers have been considered in studies of temperature related mortality and morbidity. In the US, an increased vulnerability to heat has been noted among individuals living in lower socioeconomic conditions, ${ }^{7,15}$ though this may be partly explained by a greater prevalence of air conditioning among those with higher incomes: in Europe, where home air conditioning is less common, there is less evidence of a socioeconomic gradient. ${ }^{16}$ Similarly, there was little evidence of a socioeconomic gradient in vulnerability to cold effects among a cohort of elderly people in Britain, ${ }^{17}$ which may reflect relatively good levels of heating in British social housing settings. Existing medical problems including diabetes and chronic obstructive pulmonary disorder also appear to increase the likelihood of temperatureassociated death. ${ }^{18}$ In addition to individual-level effect modifiers, some studies have noted an effect of latitude: in the US, individuals in cooler northern regions appeared to be more affected by high temperatures, while those in the warmer south appeared to be more vulnerable to cold. ${ }^{7} \mathrm{~A}$ similar phenomenon has been noted in Europe, ${ }^{10,19}$ and it has been suggested that populations familiar with local hot or cold extremes may have established adaptation measures, such as using appropriate clothing, installing heating/air conditioning, and reducing outdoor activity, and that this may at least partly explain the apparent latitude effect. ${ }^{20}$ The broad underlying hypothesis is that temperatures people are not usually familiar with, and therefore have greater difficulty adapting to on biological and behavioural levels, have a greater effect.

If the epidemiological findings suggesting associations between temperature and cardiovascular morbidity and mortality are indeed the result of a causative link, some plausible mechanism is needed. Experimental evidence suggests various possibilities: increases in arterial pressure and blood viscosity have been observed during cold exposure experiments, ${ }^{21}$ as have an increased need for oxygen and consequently an increase in the cardiac workload. ${ }^{22}$ Furthermore, red cell counts, plasma cholesterol and fibrinogen concentrations, all of which may be thrombogenic, appear to be elevated on exposure to cold. ${ }^{21,23}$ Heat exposure has also been shown under controlled conditions to lead to increases in red blood cell counts, platelet counts, and blood viscosity, as well as increases in heart rate. ${ }^{24}$ However there is a lack of data regarding the effects of temperature on more recently available measures of coagulation pathways.

There are public health motives for further clarifying the effects of temperature. Weather forecasting is reasonably accurate up to a few days in advance. With a well understood relationship between weather parameters and cardiovascular risk, those most vulnerable could be warned when the risk of cardiovascular events was likely to increase and given advice to reduce their personal risk. The UK Met Office recently set up a similar targeted warning system for chronic obstructive pulmonary disease sufferers. Under this scheme patients are alerted by an automated telephone call when the risk of disease exacerbation is likely to be elevated based on forecasts of low ambient temperature; they are given advice on keeping warm, avoiding low temperatures, and watching for warning signs of their condition worsening. It is claimed that a 20.5 to $48 \%$ reduction in hospital admissions has been achieved among practices signing up to the scheme. ${ }^{25}$ On the other hand, in the case of cardiovascular disease, 
temperature effects may be present even outside the most vulnerable groups, ${ }^{14}$ so a more widespread health education message aimed at reducing the impact of temperature changes might be of value. For example, the UK Department of Health currently has in place a heatwave plan, which aims to help organisations prepare for a heatwave and ultimately to reduce adverse health impacts. ${ }^{26}$ Such approaches should of course be subject to evaluation.

There is much room for further research. Though the effects of temperature on cardiovascular mortality overall are relatively well established, there is limited and conflicting evidence concerning more specific outcomes. There is also a need for more studies which take account of potential effect modifiers such as air conditioning, home heating, and use of cold weather clothing. A few studies have presented stratified or age-restricted data, but it is not yet clear how age, and other individual-level factors such as previous disease, affects an individual's vulnerability to weather-related effects. This article has focussed on the effects of temperature, reflecting the weight of much of the literature to date. There is relatively little evidence concerning the role of other meteorological parameters such as air pressure and humidity, and complex variables such as air mass type, which may more fully capture weather characteristics than individual measures. Finally, though measuring and describing effects of temperature and weather on cardiac outcomes is in itself of scientific interest, ultimately, it is hoped that research in this area may lead to effective public health policies. Potential interventions, which might be targeted at the most vulnerable or aimed at the whole population need to be identified and trialled with the aim of mitigating any weather-related increases in mortality or morbidity.

\section{References}

1. Griffiths C, Rooney C, Brock A. Leading causes of death in England and Wales--how should we group causes? Health Stat Q. 2005;6-17.

2. World Health Organization. The global burden of disease 2004 Update. WHO. 2004.

3. Keatinge WR, Donaldson GC. Cardiovascular mortality in winter. Arctic Med Res. 1995;54 Suppl 2:16-8.

4. Hippisley-Cox J, Coupland C, Vinogradova Y, Robson J, Minhas R, Sheikh A, et al. Predicting cardiovascular risk in England and Wales: prospective derivation and validation of QRISK2. Bmj. 2008;336:1475-82.

5. Barnett AG, de Looper M, Fraser JF. The seasonality in heart failure deaths and total cardiovascular deaths. Aust N Z J Public Health. 2008;32:408-13.

6. Bean WB, Mills CA. Coronary occlusion, heart failure, and environmental temperatures. Am Heart J. 1938;16:701.

7. Curriero FC, Heiner KS, Samet JM, Zeger SL, Strug L, Patz JA. Temperature and mortality in 11 cities of the eastern United States. Am J Epidemiol. 2002;155:80-7.

8. McMichael AJ, Wilkinson P, Kovats RS, Pattenden S, Hajat S, Armstrong B, et al. International study of temperature, heat and urban mortality: the 'ISOTHURM' project. Int J Epidemiol. 2008;37:112131.

9. Braga ALF, Zanobetti A, Schwartz J. The effect of weather on respiratory and cardiovascular deaths in 12 U.S. cities. Environ Health Perspect. 2002;110:859-63. 
10. Analitis A, Katsouyanni K, Biggeri A, Baccini M, Forsberg B, Bisanti L, et al. Effects of Cold Weather on Mortality: Results From 15 European Cities Within the PHEWE Project. Am J Epidemiol. 2008.

11. Basu R. High ambient temperature and mortality: a review of epidemiologic studies from 2001 to 2008. Environ Health. 2009;8:40.

12. Anderson BG, Bell ML. Weather-related mortality: how heat, cold, and heat waves affect mortality in the United States. Epidemiology. 2009;20:205-13.

13. Bhaskaran K, Hajat S, Haines A, Herrett E, Wilkinson P, Smeeth L. Effects of ambient temperature on the incidence of myocardial infarction. Heart. 2009;95:1760-9.

14. Bhaskaran K, Hajat S, Haines A, Herrett E, Wilkinson P, Smeeth L. Short term effects of temperature on risk of myocardial infarction in England and Wales: time series regression analysis of the Myocardial Ischaemia National Audit Project (MINAP) registry. Bmj. 2010;341:c3823.

15. O'Neill MS, Zanobetti A, Schwartz J. Modifiers of the temperature and mortality association in seven US cities. Am J Epidemiol. 2003;157:1074-82.

16. Kovats RS, Hajat S. Heat stress and public health: a critical review. Annu Rev Public Health. 2008;29:41-55.

17. Wilkinson $P$, Pattenden $S$, Armstrong B, Fletcher A, Kovats RS, Mangtani $P$, et al. Vulnerability to winter mortality in elderly people in Britain: population based study. Bmj. 2004;329:647.

18. Schwartz J. Who is sensitive to extremes of temperature?: A case-only analysis. Epidemiology. 2005;16:67-72.

19. Barnett AG. Temperature and cardiovascular deaths in the US elderly: changes over time. Epidemiology. 2007;18:369-72.

20. Eurowinter Group. Cold exposure and winter mortality from ischaemic heart disease, cerebrovascular disease, respiratory disease, and all causes in warm and cold regions of Europe. The Eurowinter Group. Lancet. 1997;349:1341-6.

21. Keatinge WR, Coleshaw SR, Cotter F, Mattock M, Murphy M, Chelliah R. Increases in platelet and red cell counts, blood viscosity, and arterial pressure during mild surface cooling: factors in mortality from coronary and cerebral thrombosis in winter. Br Med J (Clin Res Ed). 1984;289:1405-8.

22. Raven PB, Niki I, Dahms TE, Horvath SM. Compensatory cardiovascular responses during an environmental cold stress, 5 degrees C. J Appl Physiol. 1970;29:417-21.

23. Neild PJ, Syndercombe-Court D, Keatinge WR, Donaldson GC, Mattock M, Caunce M. Coldinduced increases in erythrocyte count, plasma cholesterol and plasma fibrinogen of elderly people without a comparable rise in protein C or factor X. Clin Sci (Lond). 1994;86:43-8.

24. Keatinge WR, Coleshaw SR, Easton JC, Cotter F, Mattock MB, Chelliah R. Increased platelet and red cell counts, blood viscosity, and plasma cholesterol levels during heat stress, and mortality from coronary and cerebral thrombosis. Am J Med. 1986;81:795-800.

25. UK Met Office. Healthy Outlook COPD Forecast Alert Service. [cited; Available from: http://www.metoffice.gov.uk/health/copd_forecasting.html

26. Johnson S, Bickler G. Evaluation of the Department of Health National Heatwave Plan: Health Protection Agency; 2007. 